\title{
Sistem Pencatatan Pemakaian Listrik Menggunakan Aplikasi Arduino
}

\author{
I Wayan Arsa Suteja \\ Teknik Elektro \\ Politeknik Nasional Denpasar, \\ Bali,Indonesia \\ Ars41982@gmail.com
}

\author{
Made Adi Surya Antara \\ Teknik Elektro \\ Politeknik Nasional Denpasar, \\ Bali,Indonesia \\ adisuryaantara.huawei@gmail.com
}

\begin{abstract}
Abstrak-Sistem pengukuran beban listrik adalah alat yang dirancang untuk mengukur dan memonitoring pemakaian listrik. Proses pembacaan arus listrik menggunakan sebuah sensor arus model SCT013 yang dihubungkan dengan beban pemakaian listrik. Mikrokontroler yang digunakan adalah mikrokontroler arduino yang berfungsi sebagai sistem kontrol utama yang akan dihubungkan dengan komputer, dengan tujuan kedepan beban agar bisa dimonitoring secara real time. Metode penelitian yang dilakukan adalah penelitian kuantitatif. Penelitian kuantitatif yang dilakukan adalah metoda penelitian eksperimental. Dengan melakukan eksperimen perakitan modul sensor arduino uno dan melakukan perbandingan dari pengukuran arus yang diperoleh dari pembacaan sensor arus model SCT013 terhadap alat ukur tang ampere meter. Hasil penelitian ini adalah sebuah data pengukuran pemakaian beban energi listrik rumah tangga dan persentase error dari perbandingan pembacaan sensor arus SCT013 dengan pembacaan dari alat ukur tang ampere meter. Dengan diadakannya penelitian ini, dapat memperoleh data berapa besar persentase error yang diperoleh dari penerapan sensor SCT013, sehingga nantinya dari hasil percobaan tersebut sensor SCT013 mampu memonitoring dengan baik dan benar pemakaian listrik pada beban rumah tangga
\end{abstract}

Kata Kunci - Mikrokontroler Arduino, sensor SCT013, Tang Ampere, Beban Rumah Tangga

\section{Pendahuluan}

Pada saat ini dunia teknologi berkembang dengan pesat di segala bidang. Dengan semakin majunya ilmu pengetahuan dan ilmu teknologi saat ini ditandai dengan banyak bermunculnya alat-alat yang menggunakan sistem kontrol digital dan automatisasi [1]. Di era globalisasi sekarang ini, teknologi sangat membantu aktivitas manusia agar lebih mudah dan lebih efisien. Teknologi alat elektronika adalah salah satu teknologi yang tentunya akan sangat membantu manusia dalam melakukan berbagai hal terutama dalam mengontrol pemakaian listrik [2].. Salah satu sistem kontrol sederhana untuk mengukur penggunaan listrik yang bisa kita kembangkan yaitu sistem kontrol berbasis arduino dengan menggunakan sensor arus, yaitu sensor arus non invasive model SCT013. Dengan menggunakan sistem kontrol berbasis arduino ini, diharapkan mampu mendapatkan hasil pengukuran yang tepat dan sesuai.

Dari sensor tersebut nantinya akan didapatkan kekurangan dan kelebihan, didalam memperoleh hasil pengukurannya. Terkait dengan adanya kekurangan dan kelebihan dari sensor tersebut pada studi kasus ini, maka diperlukan sebuah metoda perbandingan seberapa besar nilai presentase kesalahan atau error dari perbandingan alat ukur, baik itu sensor arus SCT013 dengan alat ukur tang ampere meter. Dengan diperolehnya hasil kesalahan atau error ini, diharapkan mampu mendapatkan korelasi kesalahan dari alat sensor arus SCT013, sehingga nantinya mampu memonitoring pemakaian listrik rumah tangga dan bisa menghitung biaya pemakaian sistem kelistrikannya dengan benar dan sesuai dengan hasil monitoring yang didapatkan.

Energi listrik merupakan penggerak dasar dari semua komponen elektronika yang terintegrasi dalam sebuah bentuk sistem kelistrikan, yang nantinya akan mendorong setiap kegiatan pada dunia industri maupun instansi. Pemakaian energi listrik tentunya perlu dikontrol mengingat program efesiensi energi yang senantiasa disampaikan pemerintah kepada masyarakat secara luas. Salah satu cara kontrol energi listrik adalah dengan monitoring secara real time ataupun pencatatan pada alat ukur yang terpasang pada sistem dari rangkaian listrik yang dimonitoring [3]. Dengan melakukan monitoring terhadap pemakaian energi listrik diharapkan penggunaan energi sesuai dengan kebutuhan yang ada serta tidak adanya pemakaian yang berlebihan atau pun pemborosan.

Ada beberapa besaran listik yang umumnya diukur dan dimonitoring penggunaannya antara lain besaran arus, tegangan, dan daya [4]. Dari ketiga besaran listrik tersebut penulis melakukan pengkajian terhadap besaran arus sebagai besaran yang bisa berubah nilainya terhadap jumlah beban yang terpasang pada sistem kelistrikan yang akan diukur ataupun dimonitoring penggunaannya. Proses monitoring besaran arus ini dilakukan dengan pemasangan alat sensor arus 


\section{Sistem Pencatatan Pemakaian Listrik Menggunakan Aplikasi Arduino}

pada point koneksi yang menghubungkan sumber beban dan sumber daya [5]. Ada beberapa penelitian yang sudah dilakukan, terkait penggunaan sensor arus sebagai alat bantu monitoring penggunaan energi listrik yang dipakai oleh pengguna baik dari rumah tangga, industri, maupun instansi.

\section{KaJian Pustaka}

Beberapa penelitian terkait monitoring pemakaian energi listrik telah dilakukan, baik dalam cakupan beban kecil seperti rumah tangga sampai dengan cakupan beban yang besar seperti distribusi penyaluran daya PLN. Penelitian pertama dengan judul "Pemodelan Alat Monitoring Keseimbangan Arus Listrik Tiga Phasa Menggunakan Arduino dan SMS Gateway Dengan Berbasis Web"[1]. Penelitian ini menggunakan mikrokontroller ATMEG328 sebagai alat pemrosesan sinyal ADC, sensor arus YHDC SCT013-030 yang bisa difungsikan sebagai sensor arus AC, modem GSM SIEMENS MC39i sebagai pengirim sms dan sebagai sms gateway pada web server dan membaca masing masing phasa arus listrik. Sebelum sensor SCT013-030 dihubungkan ke arduino atau mikrokontroller, terlebih dahulu dibuat rangkaian input sensor arus ke arduino dengan bebrapa komponen seperti resistor, kapasitor, jack female, kabel jumper, dan papan PCB. Dengan alat kontrol dan monitoring ini akan sangat membantu untuk efisiensi dan efektifitas dalam memonitor kondisi arus listrik terutama untuk arus listrik 3 phasa [1].

Penelitian kedua dengan judul "Implementasi Metode Naïve Bayes pada Sistem Stop Kontak untuk Klasifikasi Perangkat Elektronik dalam Kamar" [4]. Penelitian ini bertujuan untuk menguji, apakah sistem dapat melakukan klasifikasi terhadap perangkat elektronik yang tertancap pada stop kontak. Penerapan fungsi klasifikasi pada stop kontak ini dapat mendukung penerapan green computing pada hardware dengan penggunaan mikrokontroller. Adapun komponen yang digunakan antara lain : ATMEGA16, sensor arus YHDC SCT013-020, stop kontak, power bank, Arduino IDE NodeMCU v1.0 dan rangkaian resistor-kapasistor. Untuk menjalankan green computing pada hardware dengan mikrokontroller dibuatlah suatu terobosan pada fungsi stop kontak untuk melakukan klasifikasi pada perangkat elektronik yang tertancap pada stop kontak. Karena banyaknya jenis alat elektronik yang tersedia maka penggunaan perangkat elektronik dibatasi hanya pada perangkat elektronik dalam kamar yaitu; hairdryer, charger hp, charger laptop, setrika, dan kipas angina. Proses pembuatan sistem klasifikasi menggunakan sensor arus YHDC SCT-013-020 sebagai pembaca arus pada stop kontak. kemudian nilai arus akan diproses oleh NodeMCU v1.0 dan naïve bayes sebagai metode yang digunakan untuk mengklasifikasi. Data klasifikasi akan disimpan pada cloud penyimpanan yang nantinya dapat diakses melalui android smartphone. Pengujian dilakukan dengan membuat 5 kombinasi 3 dari perangkat elektronik sehingga terdapat 10 kombinasi. Tujuan kombinasi ini untuk mendukung program green computing, yang merupakan suatu kegiatan pembelajaran yang bisa dikatakan sebagai suatu bentuk penggunaan sumber daya teknologi secara efektif dan efisien [4].

Penelitian ketiga dengan judul "Rancang Bangun Sistem Monitoring Gangguan Pada Gardu Listrik Menggunakan Arduino dan Website [5]. Penelitian ini membahas perancangan serta pembuatan perangkat keras dan perangkat lunak untuk membangun sistem monitoring gardu listrik. Perancangan dan pembuatan perangkat keras merupakan tahapan yang dilakukan untuk mendesain dan membuat perangkat pembacaan data tegangan AC (Alternating Current) dengan sensor ZMPT101B, arus listrik AC SCT-013, dan temperatur SHT11 yang diproses oleh mikrokontroler pada arduino platform kemudian ditransmisikan melalui antarmuka ethernet. Perangkat ethernet menerima data dari arduino melalui jalur komunikasi Serial Pheriperal Interface (SPI). Modul ethernet berfungsi dalam menterjemahkan data dari arduino yang dikirim melalui jalur SPI ke modul ethernet menjadi paket data dengan arsitektur TCP/IP. Paket data yang dikirim ke webserver akan diolah kembali oleh PHP dan disimpan di database. Data ditampilkan kembali secara visual dalam bentuk grafik yang dibangun menggunakan CSS, HTML, dan framework Javascript untuk membuat tampilan beban serta kinerja gardu listrik [5].

Penelitian keempat dengan judul "Prototype Monitoring Arus, dan Suhu pada Transformator Distribusi Berbasis Internet Of Things (IoT)" [2]. Penelitian ini membahas tentang sebuah prototipe sistem monitoring parameter arus dan suhu pada transformator berbasis IoT untuk meningkatkan effisiensi ,lifetime, serta mengetahui kondisi transformator secara real time. Hal tersebut didasarkan pada timbulnya gangguan pada transformator distribusi yang mengakibatkan kerusakan pada trafo dan terputusnya penyaluran tenaga listrik ke pelanggan. Salah satu gangguan pada transformator distribusi dapat diakibatkan hubung singkat atau pembebanan arus lebih yang mengakibatkan arus naik dari nominal serta peningkatan suhu belitan maupun disekitar trafo. Adapun komponen yang digunakan antara lain : Mikrokontroler Wemos D1 R1, sensor arus YHDC SCT-01300, sensor suhu DS18B20, modul ADC ADS1115, dan Aplikasi Blynk. Rata - rata kesalahan pengukuran atau error yang dihasilkan sistem monitoring berbasis Internet Of Things (IOT) terhadap alat ukur standar, dengan pengujian arus per phasa adalah $\mathrm{R}=1,0 \%, \mathrm{~S}=1,8 \%, \mathrm{~T}=1,7 \%$ dan akurasi error suhu per phasa yakni $\mathrm{R}=3,1 \%, \mathrm{~S}=5,8 \%, \mathrm{~T}=8,0 \%$. Respon pengiriman nilai sensor terhadap interface yang terdapat pada aplikasi sangat bergantung kepada kecepatan koneksi internet yang tersedia [2].

Penelitian kelima dengan judul "Rancang Bangun Sistem Monitoring Arus Beban pada Gardu Distribusi Menggunakan Short Message Service"[3]. Penelitian ini membahas sistem monitoring arus beban dimana merupakan perangkat yang diintegerasikan pada gardu distribusi. Nilai 


\section{Sistem Pencatatan Pemakaian Listrik Menggunakan Aplikasi Arduino}

arus beban yang dibaca dan dikonversi oleh sensor, informasi waktu, dan tanggal secara real time ditampilkan pada LCD. Adapun komponen yang digunakan antara lain : Mikrokontroler Arduino Mega 2560, Modul IComSat v1.1SIM900 GSM GPRS, Modul Micro SD Card, Modul RTC (Real Time Clock), power supply, LCD, dan Sensor Arus YHDC SCT 013-000 1V. Pengimplementasian sistem monitoring arus beban dilakukan pada gardu distribusi KA0298 yang menyuplai Laboratorium Teknik Elektro Universitas Udayana. Perangkat ini dapat melakukan monitoring arus beban berdasarkan perintah yang dikirimkan melalui SMS. Perintah SMS yang dikirim dengan kode "CEKARUS" dapat diterima dan direspon oleh sistem monitoring arus beban dengan hasil balasan SMS informasi nilai arus beban fasa $R$, fasa $S$, fasa $T$ dan fasa $N$ pada gardu distribusi. Sistem data logger pada perangkat dapat digunakan untuk merekam perubahan arus beban pada gardu distribusi. Sistem notifikasi arus beban memberikan SMS peringatan jika terjadi gangguan arus beban pada gardu distribusi [3].

Berdasarkan kelima penelitian yang sudah dilakukan tersebut yang keseluruhannya mengangkat permasalahan monitoring energi listrik yang kita konsumsi setiap hari dan berkesinambungan. Adapun topik yang akan penulis teliti dalam penelitian ini adalah berjudul "Sistem Pencatatan Pemakaian Listrik Menggunakan Aplikasi Arduino”. Dalam hal ini, penulis mencoba untuk untuk menggunakan sensor arus yang bertipe sensor arus YHDC SCT013. Penelitian tentang sensor arus tipe YHDC SCT013 masih minim diteliti dan hal ini layak untuk dikaji lebih lanjut tentang akurasi maupun error yang didapatkan ketika pengunaan sensor arus YHDC SCT013. Perlu diketahui bahwa setiap pembacaan sensor pempunyai perbandingan error yang berbeda beda diperbandingan dengan kesesuaian hasil perhitungan dari penggunaan alat ukur arus seperti tang ampere meter. Hal ini perlu kita ketahui untuk melihat seberapa nilai presentase kesalahan atau error dari masing masing alat ukur sensor terhadap alat ukur besaran listrik yang ada yaitu ampere meter, didalam memonitoring pemakaian energi listrik yang kita pergunakan.

Dengan diadakannya penelitian ini, diharapkan kedepannya didapatkan sensor yang tepat untuk mendapatkan hasil pembacaan pemakaian arus listrik, sehingga pengguna mampu memonitoring pemakaian listrik dan bisa menghitung biaya pemakaian sistem kelistrikannya.

\section{METODE}

Pendekatan dalam penelitian ini adalah pendekatan kuantitatif, karena penelitian ini banyak menampilkan angka angka. Hal ini menyesuaikan dengan penjelasan penelitian kuantitatif yang mana dituntut menggunakan angka, mulai dari pengumpulan data, penafsiran data, serta menampilkan data. Adapun langkah langkah pada penelitian berikut, dapat dijelaskan pada Gambar 1 dibawah. Pada Gambar 1 dapat dijelaskan bahwa semua proses dijalankan secara terurut dimulai dengan melakukan studi literatur pendukung sesuai dengan permasalahan penelitian dan dirangkum sebagai bahan acuan penulis. Kemudian menyusun kebutuhan apa saja yang harus dipenuhi dalam membangun sistem. Tahap berikutnya, dilakukan perancangan software dan hardware dan dilanjutkan dengan implementasi hardware maupun implementasi software sesuai dengan perancangan. Proses selanjutnya setelah sistem selesai dibuat dilanjutkan dengan melakukan pengujian serta menganalisis hasil yang diperoleh. Langkah paling terakhir adalah melakukan penarikan kesimpulan.

Pada tahapan analisa desain sistem, dilakukan analisa mengenai proses pengambilan data yang terdapat dalam sensor YHDC SCT013 yang akan dijalankan oleh sistem yang terdapat pada mikrokontroller arduino.

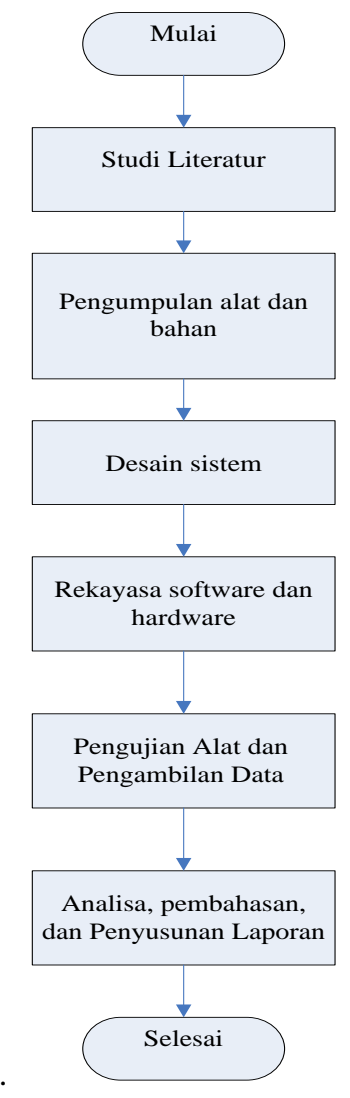

Gambar 1. Tahapan penelitian

Alur analisis desain sistem akan dijelaskan pada Gambar 3.2 dibawah, dengan tujuan alur proses sistem dapat lebih mudah dipahami. Berikut ini merupakan alur dari proses pengambilan data pada sensor YHDC SCT013 yang terdapat pada sistem yang akan dibangun. 


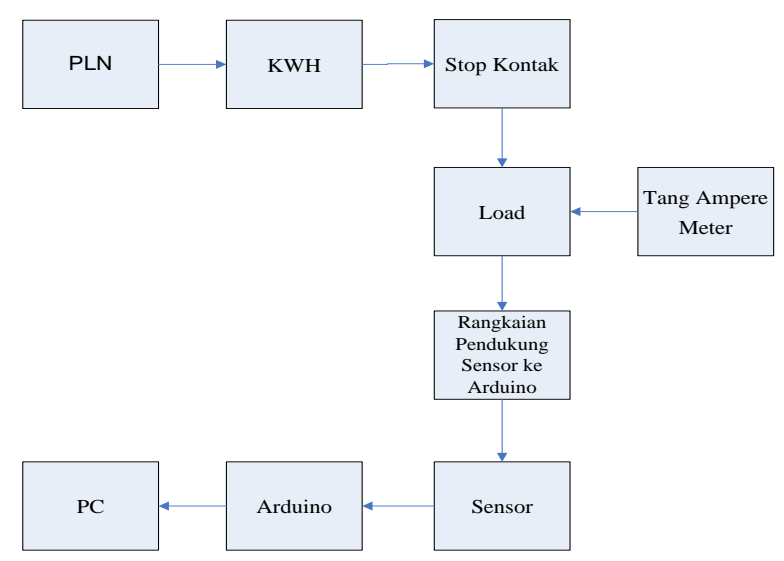

Gambar 2. Desain Sistem Pencatatan Pemakaian Listrik menggunakan aplikasi Arduino

Cara kerja rangkaian seperti pada diagram blok pada Gambar 2 adalah sebagai berikut. Sumber daya utama kelistrikan didapatkan dari jaringan listrik PLN yang tersambung pada panel KWH meter. Panel KWH yang terpasang pada instalasi rumah tangga akan mendistribusikan penyaluran daya ke masing masing stop kontak. Jika beban sudah terpasang pada stop kontak maka sensor arus YHDC SCT013 memonitoring arus yang lewat dan sekaligus menampilkan arus yang dikonsumsi oleh beban yang terpasang. Selanjutnya, besaran arus dan daya dikalikan melalui pemrograman arduino maka hasil arus dan dayanya dapat di tampilkan pada layar PC atau komputer. Fungsi rangkaian pendukung sensor ke arduino dalam diagram blok tersebut adalah sebagai pembantu proses konversi pembacaan ADC (analog to digital converter) dari sensor arus YHDC SCT013 sehingga dapat dibaca dan diolah dengan baik oleh mikrokontroller arduino.

\section{HASIL DAN PEMBAHASAN}

\section{A. Implementasi Perangkat Keras}

Implementasi perangkat keras pada sistem ini dimulai dari menghubungkan semua komponen yang dibutuhkan dalam membangun sistem monitoring. Tampilan perangkat keras sistem monitoring arus dengan mikrokontroller arduino dapat dilihat pada Gambar 4. berikut

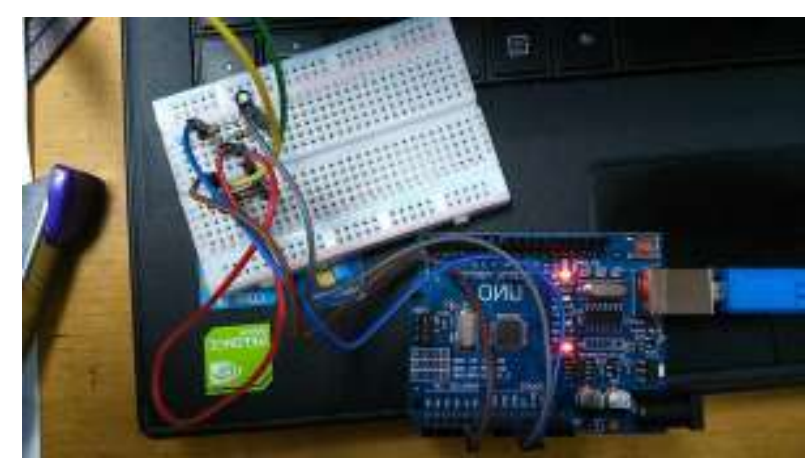

Gambar 3. Implementasi Perangkat Keras
Pada Gambar diatas merupakan implementasi sistem sistem monitoring arus. Terlihat bahwa prototype sistem ini hanya menggunakan komponen yang minim sehingga tidak akan memakan banyak tempat ketika dihubungkan dengan stop kontak.

Terdapat skematik perangkat keras dari keseluruhan sistem yang terdiri dari beberapa komponen untuk membuat sebuah perangkat elektronik yang memonitoring pembacaan arus listrik. Mikrokontroler Arduino Uno akan disambungkan dengan sensor arus YHDC SCT013 melalui rangkaian pembaca arus atau modul sebagai penghubung. Sensor arus YHDC SCT013 nantinya akan dihubungkan dengan kabel pada stop kontak untuk dapat membaca arus yang melewatinya. Sistem mikrokontroller arduino uno ini akan bekerja ketika mendapat sumber daya melalui komputer atau laptop yang terhubung.

Untuk menghubungkan sensor arus ke Arduino Uno diperlukan beberapa komponen, antara lain:

1. Resistor $33 \mathrm{Ohm}$ (didapat dengan perhitungan burden resistor)

2. Resistor $10 \mathrm{KOhm}$

3. Kapasitor 10 uf

4. Jack female $3,3 \mathrm{~mm}$

5. Kabel jumper

6. Papan PCB atau Breadboard

Berikut Gambar 4. rangkaian input sensor arus ke arduino:

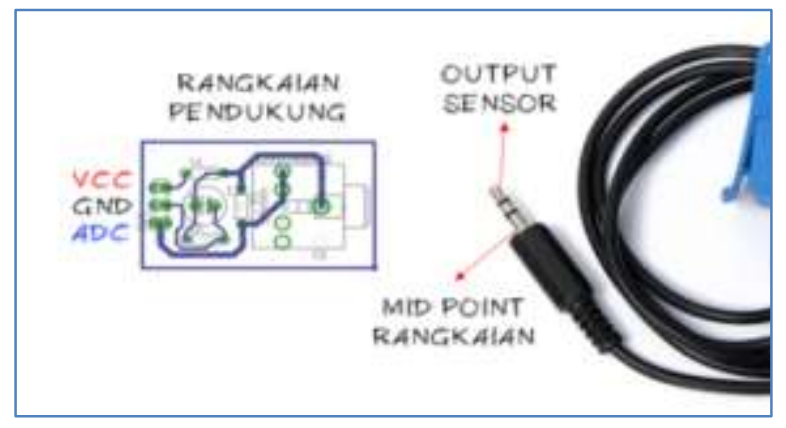

Gambar 4. Rangkaian Pendukung Modul Sensor Arus ke Arduino Uno

Perhitungan burden resistor dilakukan untuk menentukan nilai resistor yang sesuai dengan spesifikasi sensor YHDC SCT013. Langkah-langkah perhitungan burden resistor akan dijelaskan sebagai berikut.

a. Menentukan arus maksimum yang akan dihitung. Pada sistem ini digunakan sensor arus YHDC SCT013 dengan nilai maksimum 100 Ampere.

b. Mengkonversi RMS arus maksimum menjadi peakcurrent, mengalikannya dengan $\sqrt{ } 2$. Primary peak-current $=$ RMS current $\times \sqrt{ } 2=100 \mathrm{~A} \times 1.414=141.4 \mathrm{~A}$

c. Membagi peak-current dengan jumlah putaran sensor arus untuk menentukan peak-current di kumparan sekunder. Sensor arus YHDC SCT013 memiliki 2000 
putaran. Secondary peak-current $=$ Primary peak-current / no. of turns

$$
=141.4 \mathrm{~A} / 2000=0.0707 \mathrm{~A}
$$

d. Untuk meningkatkan resolusi pengukuran, tegangan yang melintasi resistor beban pada arus puncak harus sama dengan setengah dari tegangan referensi Mikrokontroller (AREF / 2). Pada sistem digunakan tegangan referensi di Arduino adalah sebesar $5 \mathrm{~V}$.

Ideal burden resistance $=(\mathrm{AREF} / 2) /$ Secondary peakcurrent

$=(5 \mathrm{~V} / 2) / 0.0707 \mathrm{~A}=2,5 \mathrm{~V} / 0,0707 \mathrm{~A}=35.4 \Omega$

$35.4 \Omega$ bukan nilai resistor umum. Nilai terdekat dari kedua sisi $35 \Omega$ adalah 30 dan $40 \Omega$. Selalu pilih nilai yang lebih kecil, atau arus beban maksimum akan membuat tegangan lebih tinggi dari AREF. Semakin jauh dari nilai ideal, semakin rendah akurasinya. Sehingga pada kasus ini digunakan burden resistor dengan nilai $33 \Omega$.

B. Implementasi Pemograman Modul pada Mikrokontroler Arduino Uno

Pada proses pemograman pada modul mikrokontroler yang dibutuhkan pada sistem ini yaitu Arduino Uno yang digunakan untuk membuat program serta melakukan kontrol secara keseluruhan, yang nantinya akan menampilkan nilai hasil pengukuran dari modul dan sensor arus YHDC SCT013. Dari program tersebut nilai dari kalibrasi yang sesui dengan alat ukur tang ampere kita masukkan nilai kalibrasi sebesar 22. Berikut tampilan program untuk pembacaan arus pada sistem Arduino Uno :

\#include "EmonLib.h"

// Include Emon Library

EnergyMonitor emon1;

// Create an instance void setup()

\{ Serial.begin(9600); emon1.current $(1,22)$;

// Current: input pin, calibration.

void loop()

$\{$ double Irms = emon1.calcIrms(1480);

// Calculate Irms only Serial.print(Irms*230.0);

// Apparent power Serial.print(" ");

Serial.println(Irms);

// Irms \}

\section{Pengujian Sensor Arus YHDC SCT013}

Proses kalibrasi sensor dilakukan agar didapatkan nilai pembacaan nilai arus yang lebih tepat setiap satuan persentase arus yang terbaca dan juga mengetahui tingkat akurasi pada sensor SCT 013. Pengujian dimulai dengan memasang rangkaian pada Gambar 5 berikut, kemudian memberikannya program.

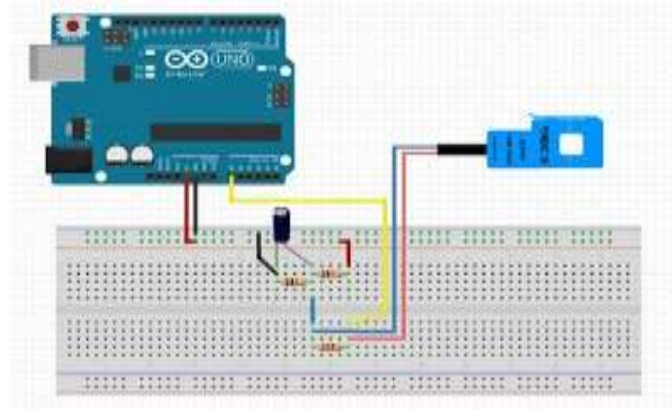

Gambar 5. Rangkaian sensor arus SCT013 000

Kalibrasi sensor dilakukan dengan mengambil salah satu sampel dari sensor SCT013 kemudian membandingkannya dengan pembacaan alat ukur digital clamp meter atau tang ampere meter. Pengujian dilakukan dalam keadaan tanpa beban atau beban nol, kemudian mengamati perubahan keluaran nilai arus. Perbandingan atau pengujian arus antara sensor YHDC SCT013 dan digital clamp meter dapat dilihat pada Tabel 1. berikut.

Tabel 1 Pengujian Perbandingan Sensor Arus dengan Clamp Meter

\begin{tabular}{|r|l|c|c|}
\hline NO & \multicolumn{1}{|c|}{ Beban } & $\begin{array}{c}\text { Alat Ukur } \\
\text { Tang Meter } \\
\text { KYORITSU } \\
(\mathbf{A})\end{array}$ & $\begin{array}{c}\text { sensor arus } \\
\text { SCT 013 (A) }\end{array}$ \\
\hline 1 & Lampu LED 5 W & 0,04 & 0,04 \\
\hline 2 & Lampu LED 7 W & 0,04 & 0,04 \\
\hline 3 & Lampu LED 11 W & 0,05 & 0,05 \\
\hline 4 & Lampu PIJAR 25W & 0,08 & 0,08 \\
\hline 5 & PC & 0,23 & 0,23 \\
\hline 6 & Charger HP & 0,04 & 0,04 \\
\hline 7 & Dispanser & 0,18 & 0,18 \\
\hline 8 & Laptop 12 Inch & 0,12 & 0,12 \\
\hline
\end{tabular}

Berdasarkan pengambilan data besaran arus yang sudah didapatkan melalui alat sensor YHDC SCT013 dan alat ukur tang ampere kyoritsu pada Tabel diatas, maka dapat kita susun grafik perbandingan sensor YHDC SCT013 terhadap alat ukur tang ampere kyoritsu sesuai dengan Gambar 6 berikut.

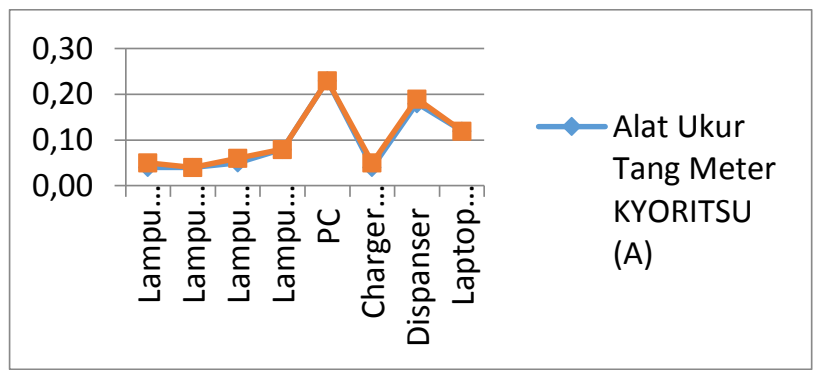

Gambar 6. Grafik Perbandingan Sensor Arus dengan Clamp Meter 
Dari hasil pengukuran pada Tabel 1 bahwa pada sensor arus ini sudah bekerja dengan baik. Hal tersebut dapat dibuktikan dengan menggunakan tang ampere pada beban yang terpasang. Misal pada beban Lampu LED 5 Watt sensor arus YHDC SCT013 arus yang terukur adalah 0,04 ampere sedangkan hasil pengukuran pada tang ampere kyoritsu adalah 0,04 ampere. Hasil pengukuran tersebut menunjukkan bahwa alat prototipe sudah dapat digunakan sebagai alat monitoring arus pada beban listrik.

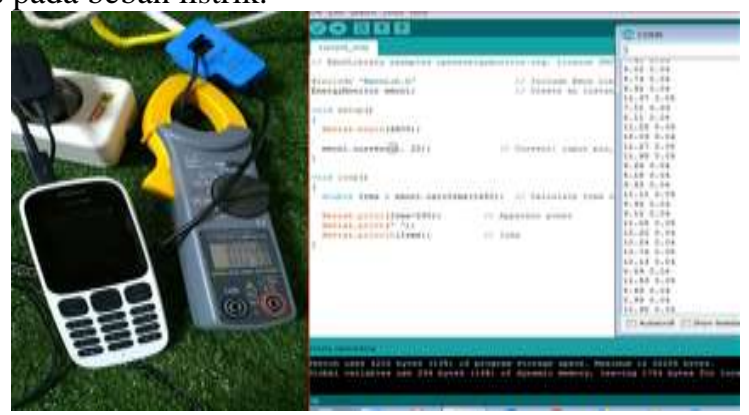

Gambar 7. Percobaan Pengukuran Tang Ampere dan Sensor YHDC SCT013

Error pada pengukuran pada sensor arus YHDC SCT013 dibandingkan dengan tang ampere dapat dihitung dengan rumus sebagai berikut :

$\%$ Error $=[($ Nilai terbaca - Nilai sebenarnya $)] /$ Nilai terbaca $\mathrm{x}$ $100 \%$

Dari perhitungan diatas didapatkan rata-rata error pada masing-masing beban untuk lampu LED 5 Watt sebesar $0 \%$. Untuk pengukuran sensor arus YHDC SCT013 terhadap tang ampere. Sedangkan untuk hasil pengujian perangkat beban yang lain dapat dilihat pada Tabel 2 berikut.

Tabel 2 Hasil Pengujian Persentase Kesalahan dari Pengukuran.

\begin{tabular}{|r|l|c|c|c|}
\hline NO & \multicolumn{1}{|c|}{ Beban } & $\begin{array}{c}\text { Alat Ukur } \\
\text { Tang Meter } \\
\text { KYORITSU } \\
(\mathbf{A})\end{array}$ & $\begin{array}{c}\text { sensor } \\
\text { arus SCT } \\
\mathbf{0 1 3}(\mathbf{A})\end{array}$ & $\begin{array}{c}\text { Error } \\
(\mathbf{\%})\end{array}$ \\
\hline 1 & Lampu LED 5 W & 0.04 & 0.05 & $20.0 \%$ \\
\hline 2 & Lampu LED 7 W & 0.04 & 0.04 & $0.0 \%$ \\
\hline 3 & Lampu LED 11 W & 0.05 & 0.06 & $16.7 \%$ \\
\hline 4 & Lampu PIJAR 25W & 0.08 & 0.08 & $0.0 \%$ \\
\hline 5 & PC & 0.23 & 0.23 & $0.0 \%$ \\
\hline 6 & Charger HP & 0.04 & 0.05 & $20.0 \%$ \\
\hline 7 & Dispanser & 0.18 & 0.19 & $5.3 \%$ \\
\hline 8 & Laptop 12 Inch & 0.12 & 0.12 & $0.0 \%$ \\
\hline
\end{tabular}

Dari hasil pengujian pada Tabel diatas, bahwa ketelitian sensor arus hampir mendekati pada alat ukur ampere meter atau tang ampere yang digunakan. Misal pada beban lampu LED 5 Watt sensor arus yang terukur pada alat prototype adalah 0,04 ampere sedangkan pada tang ampere adalah 0,04 ampere. Hal ini mengartikan error pada hasil pengukuran dengan sensor arus SCT013 jika dibandingkan dengan tang ampere sudah mendekati.

\section{KESIMPULAN}

Berdasarkan pada tahapan penelitian yang dilakukan mulai dari perancangan hardware, perancangan software, implementasi, hingga tahap pengujian perangkat monitoring arus pada beban listrik rumah tangga dapat ditarik kesimpulan dan saran yaitu: Pada penelitian ini dapat dibuat perangkat monitoring arus listrik pada beban rumah tangga berbasis Arduino Perangkat monitoring arus pada beban rumah tangga dapat memberikan informasi tingkat perubahan arus listrik secara real time. Sistem seluruhnya telah dapat melakukan monitoring perubahan arus listrik pada beban rumah tangga dengan nilai rata-rata presentase error yang rendah, menyamai alat ukur tang ampere meter

\section{Daftar Pustaka}

[1] Ajar Rohmanu, Riswandi (2016). Pemodelan Alat Monitoring Keseimbangan Arus Listrik Tiga Phasa Menggunakan Arduino dan SMS Gateway Dengan Berbasis Web. Jurnal Informatika SIMANTIK Vol.1, No.1 September 2016

[2] Axel Reinald Madjid, Bambang Suprianto (2019). Prototype Monitoring Arus, dan Suhu pada Transformator Distribusi Berbasis Internet Of Things (IoT). Jurnal Teknik Elektro. Volume 8 Nomor 01 Tahun 2019, 111-119

[3] Ignatius I Wayan Rexci Indra Parmana, Cok Gede Indra Partha, Ngakan Putu Satriya Utama (2018). Rancang Bangun Sistem Monitoring Arus Beban pada Gardu Distribusi Menggunakan Short Message Service. Majalah Ilmiah Teknologi Elektro, Vol. 17, No. $\begin{array}{lll}\text { 1,Januari } & \text {-April } & 2018\end{array}$ https://doi.org/10.24843/MITE.2018.v17i01.P03

[4] Shelsa Faiqotul Himmah, Dahnial Syauqy, Mochammad Hannats Hanafi Ichsan (2018). Implementasi Metode Naïve Bayes pada Sistem Stop Kontak untuk Klasifikasi Perangkat Elektronik dalam Kamar. Jurnal Pengembangan Teknologi Informasi dan Ilmu Komputer Vol. 2, No. 12, Desember 2018, hlm. 6000-6007

[5] Wahyu Rudiyan Saputra, Abdul Muid, Tedy Rismawan (2016). Rancang Bangun Sistem Monitoring Gangguan Pada Gardu Listrik Menggunakan Arduino dan Website Jurnal Coding, Sistem Komputer Untan Volume 04, No.2 (2016), hal. 141-150 